\title{
A MOVE STRUCTURE MODEL FOR DENTISTRY RESEARCH ARTICLE ABSTRACTS: A GENRE-BASED STUDY OF VARIATIONS AND SIMILARITIES IN EIGHT DENTISTRY SUBDISCIPLINES
}

\author{
Hesham Suleiman Alyousef
}

\begin{abstract}
The abstract is one of the most important sections in a research article (RA) because it is the first section researchers read to determine whether it is relevant to their research. The abstract provides an overview or summary of the entire article. In the dentistry discipline, the RA abstract can either be structured using headings or written as a summary. However, subdisciplinary investigations of intradisciplinary (within the same discipline) variations of move structures in dentistry RA abstracts are lacking. This study aimed to investigate the prototypical rhetorical move structure realizations of 119 English RA abstracts in eight dentistry disciplines: Oral Sciences, Periodontics, Restorative Dentistry, Endodontics, Operative Dentistry, Prosthodontics, Oral and Maxillofacial Surgery, and Orthodontics. It also aimed to investigate whether there are any intradisciplinary variations and/ or similarities between the eight dentistry subdisciplines in terms of move sequence and length. The findings showed a lack of intradisciplinary variations in the rhetorical four-move structure (Purpose-Method-Result-Conclusion) across the eight dentistry subdisciplines. The Introduction/Background move was not present in all the dentistry subdisciplines; therefore, it is optional in five subdisciplines but conventional in the Oral Sciences, Endodontics, and Oral and Maxillofacial Surgery subdisciplines since its occurrence exceeded 60 per cent of investigated RA abstracts of those subdisciplines. The analysis of the move lengths indicated the importance of the Methods and the Results moves in dental research discourse because each move constituted over 25 per cent of text space. The findings revealed the importance of drawing learners' attention to the research gap when establishing the context for a study. Future studies may employ the proposed move-analysis model for RA abstract analyses in other academic disciplines.
\end{abstract}

\section{Keywords}

rhetorical moves, move length, research article, abstract, academic writing, intradisciplinary variations, dentistry subdisciplines

\section{Introduction}

The abstract is the first section researchers read to determine whether an article is relevant to their research. Therefore, it is one of the most important sections of a research article (RA). Understanding the appropriate move structure of an abstract helps authors construct coherent and logical discourses. 
A 'move' (or a semantic unit) is defined by Swales (2004: 228) as "a discoursal or rhetorical unit that performs a coherent communicative function". While some journal editors restrain the moves in a RA by requiring a specific move structure, others simply set a word limit and/or require authors to write a concise summary of the article. Various models have been proposed for investigating RA abstracts (e.g. Bhatia 1993, Dos Santos 1996, Hyland 2000, Kanoksilapatham 2013). Structured abstracts typically follow a standard boilerplate design that includes the four moves of Purpose, Method, Results, and Conclusion (P-M-R-C). This design matches the four-move model suggested by Bhatia (1993). Conversely, Hyland (2000) proposed a five-move pattern, IntroductionPurpose-Method-Result-Conclusion (I-P-M-R-C), which separates the purpose from the introduction "due to the different roles which these two sections play in research abstracts" (Zand-Moghadam \& Meihami 2016: 3). Biber et al. (2007) argue that move-analysis was originally developed as a tool to teach non-native English-speaking authors the rhetorical structure of RAs, and it was extended to include academic and professional texts. Von Fraunhofer (2010) provided a practical research writing guide for dentistry researchers; however, the structural format of dentistry RA abstracts has not been discussed.

Move-based genre studies of the different sections of RAs have attracted many scholars. Several researchers have analyzed the generic moves of an RA abstract in the disciplines of linguistics (Zand-Vakili \& Kashani 2012, Can et al. \& Qin 2016, Khansari et al. 2016), literature (Tankó 2017), social sciences (Martín 2003), accounting (Amnuai 2019), medicine (Salager-Meyer 1990), civil engineering (Kanoksilapatham 2013) and dentistry (Shamsabadi et al. 2014, Vathanalaoha \& Tangkiengsirisin 2018). Other researchers have examined subdisciplinary move structure variations and similarities in the RA abstracts of the subdisciplines of business ( $\mathrm{Li} \&$ Pramoolsook 2015), linguistics (Pho 2008, Suntara \& Usaha 2013), science (Ngai et al. 2018), ecology (Samraj 2005) and engineering (Maswana et al. 2015, Huang 2018). Similar investigations of dentistry RA abstracts within its different sub-fields are lacking.

The present study aims to investigate: 1) the prototypical rhetorical move structure realizations of English RA abstracts in eight dentistry subdisciplines: Oral Sciences, Periodontics, Restorative Dentistry, Endodontics, Operative Dentistry, Prosthodontics, Oral and Maxillofacial Surgery and Orthodontics; and 2) whether there are any intradisciplinary (within the same discipline) variations and/or similarities between the eight dentistry subdisciplines in terms of move sequence and length of English RA abstracts. 


\section{Literature review}

Numerous studies have employed genre-based move analyses for investigating RAs or different RA sections in various disciplines. Discourse moves have been investigated from several perspectives, such as range, length, organization, and linguistic features (Can et al. 2016). Most studies have investigated the importance of a particular move in terms of 'range' (essentiality). For example, Kanoksilapatham (2005) divided moves into optional, conventional, and obligatory categories. He sets an arbitrary cut-off point to assign a category for each move, i.e. a move is 'conventional' if it occurs in 60 per cent or more of the corpora or 'optional' if its occurrence is less. An 'obligatory' move is defined as one that occurs in 100 per cent of the corpora. 'Organization' addresses how moves within an RA or a particular RA section are sequenced. Hyland (2000) argues that although 60 per cent of physics and engineering RA texts employed the Purpose-Method-Result move sequence, 75 per cent of humanities/social sciences RA texts employed the Introduction-Purpose-Result pattern. Finally, numerous studies investigated certain 'linguistic features' that are used to realize these moves, such as tense, voice, vocabulary, modals, and stance.

\subsection{Studies on generic structures of RA abstracts}

Rhetorical move/step genre analyses of various texts have proliferated enormously. Several studies have investigated the generic move structure of RA abstracts in the following disciplines: linguistics (Zand-Vakili \& Kashani 2012, Can et al. 2016, Khansari et al. 2016), literature (Tankó 2017), social sciences (Martín 2003), accounting (Amnuai 2019), medicine (Salager-Meyer 1990), civil engineering (Kanoksilapatham 2013) and dentistry (Shamsabadi et al. 2014, Vathanalaoha \& Tangkiengsirisin 2018). Vathanalaoha and Tangkiengsirisin (2018) studied the move structure of Thai dental RA abstracts and international dental RA abstracts. The researchers employed Kanoksilapatham's (2013) five-move structure of civil engineering RA abstracts: Background-PurposeMethodology-Results-Discussion (B-P-M-R-D). However, the sampling procedure of the 120 experiment-based dentistry RA abstracts was based only on the top five dental journals with the highest impact factor. The results showed that the Purpose-Methods-Results-Discussion (P-M-R-D) moves are obligatory since they occurred in 100 per cent of the corpora whereas the Background move is conventional $(60.9 \%)$. The findings showed that the B-P-M-R-D move sequence is the most common sequence used by international journals $(48 \%)$. However, the researchers should have substituted the Background move with the Introduction since most dentistry RA abstracts provide little context. Moreover, 
the Background move was only present in 60.9 per cent of the RA abstracts in the international dataset. Vathanalaoha and Tangkiengsirisin (2018: 12), however, argue that "the inclusion of Background and Discussion moves is of significance for the academic discourse of dentistry". Their findings, therefore, cannot be generalized to all dentistry subdisciplines, which include both experimental research studies and laboratory and clinical research studies (e.g. Oral Sciences, Operative Dentistry). The international journals Vathanalaoha and Tangkiengsirisin investigated only included three sub-fields of dentistry: General Dentistry, Periodontics and Endodontics. Shamsabadi et al. (2014) investigated the similarities/differences in the use of moves in 50 dentistry RA abstracts written in English by native scholars and Iranian scholars. The native scholars' dataset was extracted from an Esthetic and Restorative Dentistry journal, whereas the other sub-corpora were elicited from an Iranian general medicine journal rather than a specialized dentistry journal. This in turn could have resulted in mixed confounding results. The findings revealed that while most of the Iranian authors employed the Introduction move in their RA abstracts, the native authors paid less attention to this move. This suggests that dentistry RA abstracts should possess the three conventional moves Method-Result-Conclusion. The authors, however, did not indicate whether the Purpose move was essential. Notably, neither of the two aforementioned studies investigated the length of each move or variations/ similarities in the move sequence across dentistry subdisciplines. In addition to the existing differences and similarieties between disciplines, rhetorical move structure variations and similarities in RA abstracts may also be found within the sub-fields of a particular discipline.

However, a few studies have examined subdisciplinary move structure variations and similarities in RA abstracts: business (Li \& Pramoolsook 2015), linguistics (Pho 2008, Suntara \& Usaha 2013), science (Ngai et al. 2018), ecology (Samraj 2005) and engineering (Maswana et al. 2015, Huang 2018). Subdisciplinary variations were identified in Li and Pramoolsook's (2015) study of 64 RA abstracts in two business fields, marketing and management. The researchers aimed to investigate whether business abstracts followed Hyland's (2000) five-move model (I-P-M-R-C). The dominant move structure in the two subdisciplines was Introduction-Purpose-Product, while there were differences in the use of the Introduction, Method, and Conclusion moves. Huang (2018) investigated the move structure in $60 \mathrm{RA}$ abstracts from three sub-fields of marine engineering discipline: automatic control, structure and dynamic, and heat and flow. The findings showed that the move structure Purpose-MethodResult (P-M-R) was the most frequent in all marine engineering RA abstracts, whereas the Introduction move was the least frequent. Perceived variations in the 
frequency of moves showed that the automatic control RA abstracts contained fewer instances of the Result move but more of the Discussion move than the other two sub-fields. The lack of a common move pattern was revealed in Maswana et al.'s (2015) study of the move structure in 67 full-length engineering RAs from five subdisciplines: structural engineering, environmental engineering, electrical engineering, chemical engineering, and computer science. Only the Purpose and Results moves were conventional in the RA abstracts, except for the Purpose move in chemical engineering abstracts. A study conducted by Samraj (2005) investigated the move structure in $24 \mathrm{RA}$ abstracts from two related disciplines, wildlife behaviour and conservation biology. That study concluded that the move structure of abstracts varies between and across different disciplines. Suntara and Usaha (2013) employed Hyland's (2000) five-move model I-P-M-R-C in their investigation of the move structure in $200 \mathrm{RA}$ abstracts of two related disciplines: linguistics and applied linguistics. Although the most frequent pattern was P-M-R-C, there were variations in the Conclusion move, which was optional in linguistics but conventional in applied linguistics.

The lack of a common subdisciplinary move pattern in the RA abstracts of a particular discipline can be ascribed to the differences in the nature of research in each field, i.e. its communicative purpose. Similar subdisciplinary genre-based investigations of RA abstracts in dentistry subdisciplines are lacking.

The reviewed literature indicates that subdisciplinary investigations of intradisciplinary variations of move structure and move length in dentistry RA abstracts are pertinent. The findings may be valuable for novice dentistry authors apprenticing disciplinary academic writing of RA abstracts to access the discourse of their community of practice (Lave \& Wenger 1991). As Ngai et al. (2018: 1) state, "understanding and observing the disciplinary rhetorical choices and communication conventions will allow scientists to align the abstracts of their studies with the expectations of the targeted audience". It is helpful for dentistry scholars to understand the rhetorical move sequence and move length differences in RA abstracts within each dentistry subdiscipline. Although one might not expect any differences among dentistry subdisciplines, the present study investigated the similarities and determined whether there are any variations in the rhetorical move structure and move length.

\section{Methodology}

\subsection{Theoretical framework}

An initial analysis of the moves in the eight dentistry subdisciplines revealed that Bhatia's (1993) four-move P-M-R-C model was not suitable for the present 
study because there is a systematic distinction between Purpose and Introduction. Hyland's (2000) five-move pattern (I-P-M-R-C) (Table 1) was adopted in the present study to investigate the moves in the RA abstracts of eight dentistry subdisciplines because it is a widely applied model in the study of RA abstract of various academic disciplines. In his study of RA abstracts across seven science disciplines, Hyland (2000) distinguished the Purpose move from the Introduction since the latter provides background for the study and reveals the research gap. A move can be realized by a clause, a sentence, or several sentences.

\begin{tabular}{|l|l|l|}
\hline Move & Hyland's model & Function \\
\hline M1 & Introduction & Establish the context of the study. \\
\hline M2 & Purpose & Indicate the aim of the study. \\
\hline M3 & Method & Provide information on materials, subjects, procedures, etc. \\
\hline M4 & Result & State main findings, the arguments and what was done. \\
\hline M5 & Conclusion & $\begin{array}{l}\text { Interpret or extend results, draw inferences and point to research } \\
\text { limitations and wider implications. }\end{array}$ \\
\hline
\end{tabular}

Table 1: Hyland's (2000) move structure framework

Hyland's original model included the move Product, which was later changed to Result.

\subsection{Data}

In this study, seventeen RA abstracts from each of the dentistry subdisciplines were selected from high-impact journals to examine whether there were variations in the generic move structure and move length in the RA abstracts across the subdisciplines (Table 2). Notably, the International Journal of Periodontics and Restorative Dentistry covers two disciplines, Periodontics and Restorative Dentistry. A total of 119 abstracts $(28,847$ words) were selected. The decision to select 17 RA abstracts in each subdiscipline was deemed sufficient to compare between the dentistry subdisciplines and to provide invaluable insights for dentistry academic practice because more data yields more reliable findings. Furthermore, most previous subdisciplinary studies selected twelve to twenty RA abstracts in their investigation of the move structure in each subdiscipline. The high-ranking journals were nominated by expert informants who specialized in the eight dentistry subdisciplines. The data selection criterion of whether the RAs were written by native or non-native authors was not considered since the RAs were published in high-ranking journals. Although four of the seven journals did not specify a word limit for the RA abstract, each abstract ranged from 200 to 300 words in length. 


\begin{tabular}{|c|c|c|c|c|c|c|c|c|}
\hline No. & $\begin{array}{l}\text { Dentistry } \\
\text { subdiscipline }\end{array}$ & Journal & $\begin{array}{l}\text { Impact } \\
\text { Factor }\end{array}$ & $\begin{array}{l}\text { No. of } \\
\text { RAs }\end{array}$ & $\begin{array}{l}\text { Word } \\
\text { Limit }\end{array}$ & \begin{tabular}{|l|} 
Word \\
Count
\end{tabular} & Structured & $\begin{array}{l}\text { Move } \\
\text { Structure }\end{array}$ \\
\hline 1 & Oral Sciences & \begin{tabular}{|l|} 
European \\
Journal of Oral \\
Sciences
\end{tabular} & \begin{tabular}{l|}
2.220 \\
$(2019)$
\end{tabular} & 17 & 200 & 3,668 & No & N/A \\
\hline $2-3$ & $\begin{array}{l}\text { Periodontics } \\
\text { \& Restorative } \\
\text { Dentistry }\end{array}$ & $\begin{array}{l}\text { International } \\
\text { Journal of } \\
\text { Periodontics } \\
\text { \& Restorative } \\
\text { Dentistry }\end{array}$ & \begin{tabular}{|l|}
1.513 \\
$(2019)$
\end{tabular} & 17 & N/A & 2,688 & No & N/A \\
\hline 4 & Endodontics & \begin{tabular}{|l|} 
Journal of \\
Endodontics
\end{tabular} & \begin{tabular}{|l|}
3.118 \\
$(2019)$
\end{tabular} & 17 & 250 & 4,524 & Yes & $\begin{array}{l}\text { I-P-M- } \\
\text { R-C }\end{array}$ \\
\hline 5 & $\begin{array}{l}\text { Operative } \\
\text { Dentistry }\end{array}$ & $\begin{array}{l}\text { Operative } \\
\text { Dentistry }\end{array}$ & \begin{tabular}{|l|}
2.213 \\
$(2019)$ \\
\end{tabular} & 17 & N/A & 4,716 & No & N/A \\
\hline 6 & Prosthodontics & \begin{tabular}{|l|} 
Journal of \\
Prosthodontics- \\
Implant \\
Esthetic and \\
Reconstructive \\
Dentistry \\
\end{tabular} & \begin{tabular}{|l|}
2.187 \\
$(2019)$
\end{tabular} & 17 & N/A & 4,912 & Yes & P-M-R-C \\
\hline 7 & $\begin{array}{l}\text { Oral \& } \\
\text { Maxillofacial } \\
\text { Surgery }\end{array}$ & $\begin{array}{l}\text { British Journal } \\
\text { of Oral and } \\
\text { Maxillofacial } \\
\text { Surgery } \\
\end{array}$ & $\begin{array}{l}1.061 \\
(2019)\end{array}$ & 17 & 250 & 3,448 & Yes & P-R-C \\
\hline 8 & Orthodontics & $\begin{array}{l}\text { European } \\
\text { Journal of } \\
\text { Orthodontics }\end{array}$ & \begin{tabular}{|l|}
2.202 \\
$(2019)$
\end{tabular} & 17 & 250 & 4,891 & Yes & $\begin{array}{l}\text { I-P-M- } \\
\text { R-C }\end{array}$ \\
\hline & & & Total & 119 & & 28,847 & & \\
\hline
\end{tabular}

Table 2: Summary of key features of the data

The word limits stipulated by each journal, however, do not seem to have affected the move structure of the abstracts produced. For example, although the Endodontics journal's authors were restrained to a 250-word limit, the total word count was similar to the Operative Dentistry and Prosthodontics journals, which did not contain a word limit. The moves were structured with explicit headings in four of the seven selected journals. For example, the guidelines of the Oral and Maxillofacial Surgery journal state that "the abstract should state briefly the purpose of the research, the principal results, and major conclusions". Thus, the investigation of the rhetorical move structure in the eight dentistry subdisciplines will reveal whether the authors of these four journals employed the move structure set by their respective journals. The selected 119 RAs were published during the years 2018 and 2019. They were downloaded from the databases 
and converted from the .pdf format to the .text format. Then, the abstracts were manually checked for conversion accuracy and saved in a separate Word file.

\subsection{Procedures and instrumentation}

The moves were identified and coded manually based on the communicative purpose (or function) of each move. Because the researcher was not a member of this community of practice, an inter-coder step was implemented in which a practicing dentist provided feedback after revising the codings to yield reliable results. To decrease the level of subjectivity, the researcher ensured that the interrater was one of the top five dentists in his group. Moreover, the rhetorical moves were already known by the practicing dentist since these are explicitly stated in some dentistry RA abstracts. The unit of analysis was the rhetorical unit (or the clause) because there were instances in which two moves were embedded (or merged) into one sentence. Because the study of moves is concerned with the communicative function, such incidences were annotated as two moves rather than one, as performed by Li and Pramoolsook (2015), who preferred to choose the dominant move. Each move boundary was identified and marked even if it occurred mid-sentence. Following Kanoksilapatham (2005), move categorization was based on range or essentiality. Thus, an arbitrary cut-off frequency (or occurrence rate) of 60 per cent was employed to measure move stability in the RA abstracts. A move is labelled 'conventional' if it occurs in 60 per cent or more of the corpora (i.e. the RA abstracts) and 'optional' (non-essential) if it occurs in less than 60 per cent. An 'obligatory' (or essential) move was defined as occurring in 100 per cent of the corpora. Kanoksilapatham (2005: 272) argues that "the cut-off frequency of 60 per cent of occurrence was arbitrarily established as a potential measure of move stability". The identification of a move ratio is based on the total number of moves in a given discipline. A move to total moves ratio for a discipline with a five-move structure is 20 per cent $(100 \%$ divided by 5). The present study calculated a 'conventional' move by dividing the total occurrences of a given move by the total number of moves in the RA abstracts and then multiplying the result by 100 .

Conversely, a move length in RA abstracts is based on the ratio of move length to the total length of all the moves. A move length is calculated in the abstract section by dividing the total word count (or text space) within a move-tag by the total number of words for all the moves and then multiplying the result by 100 . Thus, according to Cross and Oppenheim (2006), a move constituting 25 per cent or more of text space was considered an 'obligatory' (or dominant) element of the RA abstract since this indicates its importance in scientific research discourse. 


\section{Results and discussion}

The next section attempts to answer research aim one, i.e. to investigate and discuss the prototypical rhetorical move structure realizations of English RA abstracts in the eight dentistry subdisciplines.

\subsection{The rhetorical move structure of English dentistry RA abstracts}

A proposed move-analysis model was established after the initial analysis of the 119 RA abstracts in the eight dentistry subdisciplines (Table 3). A step is a subunit that falls under a specific move. An optional step (Research Gap) was added under move 1, and the optional steps Implications/Suggestions for further research and Limitations were added under move 5. Each of these steps aims "to achieve the purpose of the move to which it belongs" (Biber et al. 2007: 24). The numbers in Table 3 represent the total number of abstracts that contained the move within the indicated subdiscipline. As stated earlier, the model was primarily based on Hyland's (2000) I-P-M-R-C move-analysis model.

The findings revealed that the P-M-R-C four-move structure was dominant in the eight dentistry subdisciplines, whereas the Introduction move appears to be conventional or optional in some subdisciplines. The move pattern results converge with some aspects in Vathanalaoha and Tangkiengsirisin's (2018) study, which revealed the four obligatory moves (P-M-R-D) in dentistry RA abstracts. Although the last dominant move in the present study is the Conclusion, it was the Discussion in Vathanalaoha and Tangkiengsirisin's study. The findings in the present study revealed that $112(94.12 \%)$ of 119 abstracts employed the fourmove structure (P-M-R-C) whereas only 117 (23.4\%) of 500 abstracts in Ngai et al.'s (2018) study across five science disciplines (life, Earth, formal, physical and social sciences) employed this structure. This indicates that the dentistry discipline has a distinctive move structure. Maswana et al.'s (2015) study of five engineering subdisciplines indicated the lack of common conventional move patterns across these subdisciplines, which they ascribed to differences in the nature of research in each field. Only the Purpose and Results sections were conventional in the RA abstracts across the five subdisciplines except chemical engineering. 


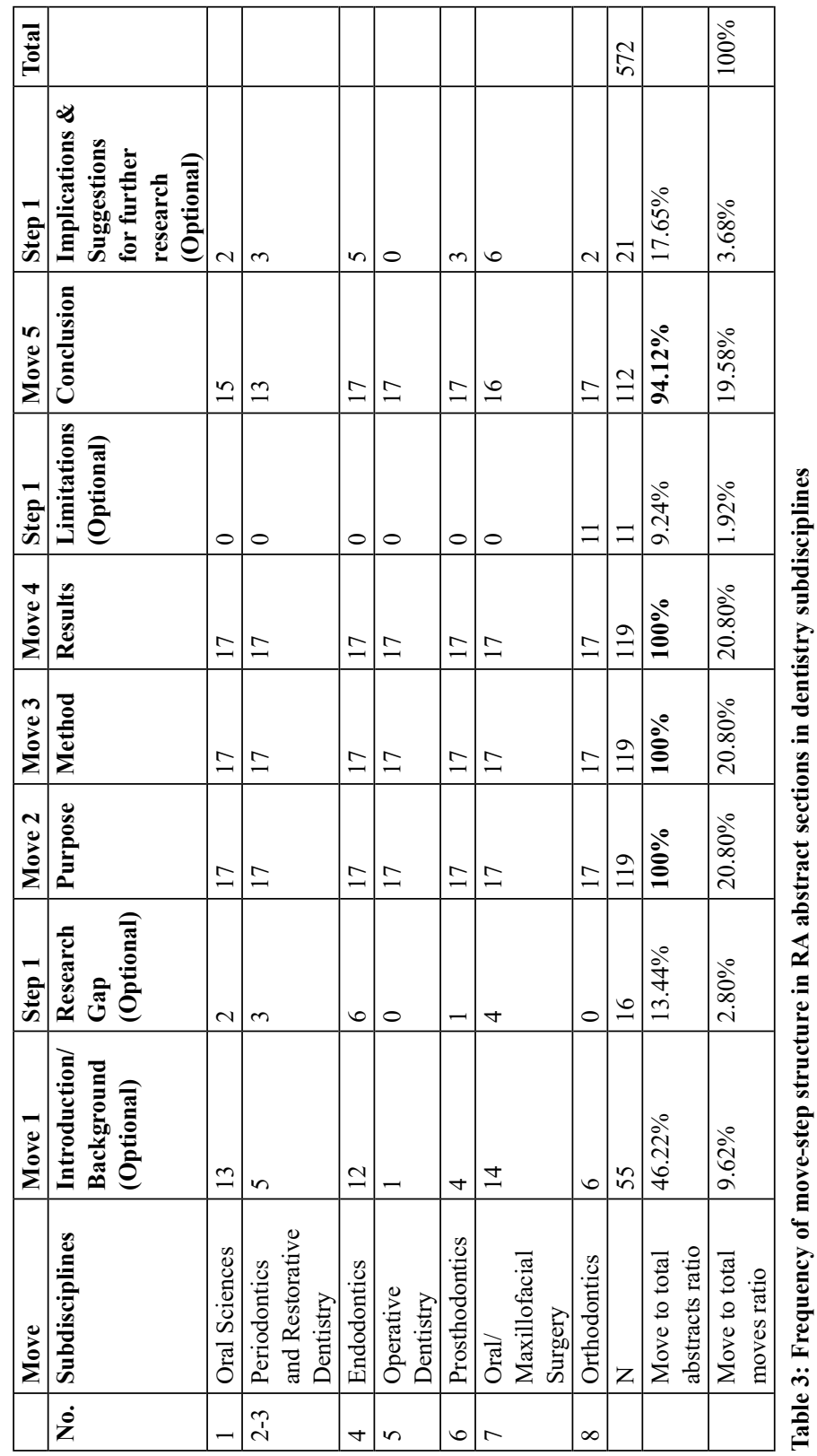


As stated earlier in Section 3.2, the practice of using structured moves with explicit headings appeared to differ across subdisciplines. The findings indicate that the Oral Sciences, Endodontics, and Oral/Maxillofacial Surgery subdisciplines adapt Hyland's (2000) five-move conventional structure I-P-MR-C. The Endodontics journal's guidelines for an abstract require authors to use a structure that is to some extent in line with Hyland's (2000) five-move structure. Although Hyland considered the Purpose move an additional move after the Introduction, it is considered in this journal as a step under move 1, the Introduction. Unfortunately, most of the authors used the heading Introduction without situating their research; instead, they started by stating the research aims. Consequently, this was coded as move 2 (Purpose), even though the authors used the heading Introduction. Although the instructions in the Orthodontics journal state that "appropriate subtitles for the Abstract include Background/ Objectives, Materials/Methods, Results, Limitations, Conclusions/Implications" (Instructions to authors 2021), eleven authors did not provide context for their study. This structure was established by Bhatia (1993), except for the Limitations move, which was presented as a separate move before the last one, rather than a step under the last move (Conclusion). Likewise, the Prosthodontics-Implant journals require authors to provide the four headings P-M-R-C. The lack of an introduction may be ascribed to the fact that most scientific dentistry RA abstracts do not require this move. Thus, all the examined abstracts in the Prosthodontics journal lacked an introduction. Only six authors provided background information to situate their research, as established by author guidelines. Although the selected Oral/Maxillofacial Surgery journal requires authors to include only the research purpose, principal results, and major conclusions in the abstract, most of the authors in the examined RAs provided an Introduction and Methodology of their research in their abstracts.

Finally, some dentistry journals do not specify an abstract structure in the author guidelines but only ask authors to provide a summary of the complete manuscript (Table 2). Although the Oral Sciences journal guidelines do not require the explicit insertion of headings within the abstract, thirteen authors employed Hyland's (2000) I-P-M-R-C move structure. Conversely, although the authors were expected to write a summary, some of the abstracts in the Operative Dentistry included the following headings: P-M-R-C. This finding aligns with Cross and Oppenheim's (2006) study, which showed that not all authors follow the guidelines. 
The next two sections attempt to answer research aim two, i.e. to investigate whether there are any intradisciplinary variations and/or similarities between the eight dentistry subdisciplines in terms of move sequence and length of English RA abstracts.

\subsection{Intradisciplinary variations/similarities in move structure}

The findings from the current study for each RA abstract move/step in the eight dentistry subdisciplines are presented and discussed in the next section with illustrative examples to provide a detailed picture of the key features of each subdiscipline.

\subsubsection{Move 1: Introduction/Background}

Following Kanoksilapatham's (2005) approach, this move is considered 'conventional' in the Oral Sciences (76.47\%), Endodontics (70.59\%) and Oral/ Maxillofacial Surgery (82.35\%) subdisciplines since its occurrence exceeded 60 per cent of the investigated RA abstracts (Table 3).

(1) Polydopamine-templated hydroxyapatite ( $t H A)$ is a type of nano-biomaterial that can promote osteogenesis in bone tissue engineering. (Oral Sciences)

(2) In regenerative endodontics, irrigation is an important step to ensure the success of treatment. EDTA as a common irrigant has been recommended in the American Associations of Endodontists guidelines. (Endodontics)

(3) Rigid external distraction is currently used to correct severe maxillary hypoplasia. (Oral \& Maxillofacial Surgery)

This indicates the importance of this move in these three dentistry subdisciplines. The author guidelines in the Endodontics and Orthodontics journals require authors to employ this move in the RA abstract (Table 2). This move, however, rarely occurred in the Orthodontics journal and the other four dentistry subdisciplines: Periodontics, Restorative Dentistry, Operative Dentistry and Prosthodontics. Moreover, 14 of the 17 Oral and Maxillofacial Surgery authors situated their research, although the guidelines of the journal did not require the Introduction/Background move. The option of a structured vs. non-structured (Table 2) abstract does not seem to affect the authors' choice of move structure. Thus, this indicates that the discourse structure of Oral and Maxillofacial Surgery RA abstracts is being updated. As Ferguson (2013: 249) argues, the discourse structure of RAs is constantly being updated by scholars since "genres, of course, are not static constructs". The use of the Introduction 
move in Oral and Maxillofacial Surgery subdiscipline confirms Hyland's (2000) argument that there is an increasing trend of using this move in RA abstracts.

Most of the authors in the five dentistry subdisciplines did not situate their research by writing an introductory sentence(s). This finding converges with Shamsabadi et al.'s (2014) note that less attention was being given to the Introduction move by native authors of Esthetic and Restorative Dentistry RA abstracts. Since the Introduction/Background move did not appear in all eight dentistry subdisciplines, it is a non-obligatory move that authors can choose when writing an abstract (Swales 2004). Thus, this move is considered non-essential (or optional) in the four subdisciplines.

Although 55 (46.22\%) of the 119 abstracts in the eight dentistry subdisciplines employed the Introduction/Background move, only twelve $(2.4 \%)$ of 500 RA abstracts employed this move in Ngai et al.'s (2018) study of the generic structure across five science disciplines: Earth, formal, life, physical, and social sciences.

The Research Gap step is optional since its frequency was below 60 per cent in the following six dentistry subdisciplines: Oral Sciences, Periodontics, Restorative Dentistry, Endodontics, Prosthodontics, and Oral and Maxillofacial Surgery. This step, however, was not required in Operative Dentistry and Orthodontics. Although pointing out a research gap is an important step in establishing context for a study, most dentistry scholars failed to underscore this step. Only 16 of 119 RA abstracts (13.44\%) presented the Research Gap step: two in Oral Sciences, three in Periodontics and Restorative Dentistry, six in Endodontics, one in Prosthodontics and four in Oral and Maxillofacial Surgery.

(4) However, because of its possibly desiccating effect, some countries do not advocate the use of glycerol. (Oral Sciences)

(5) However, very little evidence of long-term results is available. (Periodontics \& Restorative Dentistry)

(6) However, this is associated with a second surgical site that increases surgical time and patient morbidity. (Periodontics \& Restorative Dentistry)

The Research Gap step is considered optional in the eight dentistry subdisciplines. Interestingly, three authors not only situated the research topic in move 1 but also explicitly stated the research gap within this move.

(7) Torture victims often show symptoms of dental anxiety when receiving dental care [Introduction/Background], but little systematic research is available [Gap]. (Oral Sciences) 
(8) Many indices and scoring systems exist for assessing skeletal patterns and malocclusion [Introduction/Background] but none have been universally adopted by teams providing orthognathic surgery in the UK [Gap]. (Oral and Maxillofacial Surgery)

This indicates that some authors in the Oral Sciences and Oral and Maxillofacial Surgery journals chose to merge the Introduction/Background move and Gap steps into one sentence, likely because of word limit constraints of 200 and 250 words respectively in the two subdisciplines.

\subsubsection{Move 2: Purpose}

The results from this study indicated that Purpose, Methods, and Results are treated as essential (or obligatory) moves since they occurred in all the the RA abstracts (Table 3). This finding corresponds with Dos Santos's (1996) and Tseng's (2011) studies, which revealed that these three moves were more frequent in applied linguistics RA abstracts than the other moves.

(9) The aim of this study was to investigate the management of incipient caries lesions in adults with two preventive protocols. (Operative Dentistry)

(10) This case series aimed to clinically and histologically evaluate porcine-derived membrane used for vertical thickening of thin soft tissues. (Periodontics \& Restorative Dentistry)

All the authors tended to commence their abstracts with this move without writing an introductory sentence(s) to outline their study aims. Notably, the authors of Endodontics, Prosthodontics, Orthodontics, and Oral and Maxillofacial Surgery employed this move because it was required in the journal guidelines (Table 2).

As stated earlier in Section 3.3, there were instances where the Purpose and Methods moves were embedded in one sentence. Embedding these two moves only occurred in the Oral and Maxillofacial Surgery RA abstracts. Only seven $(41.17 \%)$ of the 17 authors stated the purpose of their research (move 2) along with the methodology (move 3).

(11) In this prospective study, we meticulously searched for more examples [Purpose] using both formalin-fixed cadavers and neck dissections [Method]. (Oral $\&$ Maxillofacial Surgery)

(12) To explore how deprivation affects the incidence of facial fractures in the north east of England [Purpose], we reviewed 1096 patients who were admitted to the 
oral and maxillofacial surgical (OMFS) unit at Sunderland Royal Hospital for treatment of a facial fracture between December 2013 and December 2017. Levels of socioeconomic deprivation, which were obtained from postcodes and the UK Government Open Data Communities database, were compared with a random sample of deprivation data from the catchment area of our hospital [Method]. (Oral \& Maxillofacial Surgery)

The combination of the Purpose-Method moves in RA abstracts is not surprising due to the compact nature of abstracts (i.e. word limit), as authors must present much information in a concise structure. This pattern demonstrates the authors' advanced writing skills where each aim is followed by the procedure, thus keeping the reader focused. This finding corresponds with Huang's (2018) study of the move structure in three sub-fields of marine engineering RA abstracts, although the frequency of occurrence was higher than in the Oral and Maxillofacial Surgery RA abstracts. Instances of embedded Method-Result moves in Huang's (2018) study mostly occurred in the structure and dynamic $(80 \%)$ and heat and flow (85\%) subdisciplines, whereas only six instances were found in the automatic control subdiscipline (30\%).

\subsubsection{Move 3: Methods}

As stated in the previous section, this move is considered an obligatory move in all the eight dentistry subdisciplines since it occurred in all 119 abstracts (Table 3). Although the journal guidelines of the Oral Sciences, Periodontics and Restorative Dentistry, and Operative Dentistry subdisciplines (Table 2) did not structure the moves, all authors employed this move.

(13) Four groups of bilayer zirconia crowns (with 10 crowns in each group) were produced by hard- or soft-machining technique, with the following four different margin designs: chamfer preparation (control); slice preparation; slice preparation with an additional cervical collar of $0.7 \mathrm{~mm}$ thickness; and reduced occlusal thickness $($ to $0.4 \mathrm{~mm}$ ) on slice preparation with an additional cervical collar of $0.7 \mathrm{~mm}$ thickness. Additionally, 10 hard-machined crowns with slice preparation were veneered and glazed with feldspathic porcelain. In total, 90 crowns were loaded centrally in the occlusal fossa until fracture. (Oral Sciences)

(14) In this observational series, three patients with gingival recession (average gingival margin [GM]: $3.16 \pm 1.13 \mathrm{~mm}$ ) showing Miller Class I to III gingival recession were treated with cryopreserved umbilical-cord allografts. (Periodontics $\&$ Restorative Dentistry) 
Notably, the authors of the Endodontics, Orthodontics, and Prosthodontics subdisciplines employed this move because it was required in the journal guidelines. Interestingly, all the Oral and Maxillofacial Surgery authors employed this move even though the author guidelines did not require its use: "the abstract should state briefly the purpose of the research, the principal results and major conclusions" (Guide for Authors 2021).

From January 2005 to September 2017, 240 patients were recruited at the Shanghai Ninth People's Hospital and divided into experimental $(n=89)$ or control $(n=151)$ groups. The experimental group was treated by a two-step suture technique, while the control group had conventional sutures. Statistical differences were assessed using the chi squared and t tests, as appropriate. (Oral \& Maxillofacial Surgery)

This indicates the crucial communicative function of the Methods in scientific research inquiry. As Bhatia (1993: 82) states, "discussion of the methodology is crucial in research abstracts, whereas it is rarely mentioned in article introductions". In this move, dentistry scholars usually provide a detailed description/discussion of the research design, data and procedures used in their study. The use of this move in all dentistry subdisciplines contrasts with the findings in some studies (Martín 2003, Samraj 2005, Li \& Pramoolsook 2015) that reported a low occurrence of this move. As stated in Section 3.3, Li and Pramoolsook (2015) attribute the low occurrence of this move in management and marketing RA abstracts to not annotating this move when it is embedded in another dominant move. As this move appeared in only half of the conservation biology and wildlife behavior abstracts, Samraj (2005: 147) concludes that "the abstract is not a mere synopsis of the research article".

\subsubsection{Move 4: Results}

Similar to the previous two moves, the Results move is considered obligatory in all dentistry subdisciplines because it occurred in all 119 abstracts (Table 3). This finding is in line with Vathanalaoha and Tangkiengsirisin's (2018) study of the generic structures of international dental RA abstracts, in which the Results move was obligatory because it occurred in all the abstracts of General Dentistry, Periodontics and Endodontics sub-fields. It also converges with Shamsabadi et al.'s (2014) findings, which indicated that this move was employed by 96 per cent of the native English writers of Esthetic and Restorative Dentistry RA abstracts. Authors of the Endodontics, Prosthodontics, Orthodontics, and Oral and Maxillofacial Surgery subdisciplines employed this move in their RA abstracts because it was required in the journal guidelines (Table 2). The Results move in 
the dentistry RA abstracts documents mostly include numerical (quantitative) data, such as means, frequencies, and statistical significance rate, regardless of whether a research study is experimental, laboratory or clinical.

(16) The mean weight ( $\pm S D)$ of meal intake, chewing rate, and number of chews per mouthful were $261.4 \pm 78.9 \mathrm{~g}, 94.4 \pm 13.5$ chews min-1, $19.2 \pm 6.4$ chews per mouthful, respectively. Chewing rate was not correlated with the number of chews per mouthful. The multivariable linear regression showed that meal intake was significantly positively associated with chewing rate, meal duration, and BMI, but inversely associated with the number of chews per mouthful (adjusted $R 2=0.42$ ). (Oral Sciences)

(17) The area between the central incisors was the widest, with a mean (SD) of 2.42 (0.68) $\mathrm{mm}$ in the lower, and 4.27 (0.99) $\mathrm{mm}$ in the upper, region followed by the space between the canines and lateral incisors. The minimum interproximal spaces in the lowest area were between 1.1 and $1.5 \mathrm{~mm}$. (Oral \& Maxillofacial Surgery)

Moreover, most authors interpreted the meanings underlying the numerical data. This is expected since they are required to interpret the output data of the statistical tests. Thus, the Results move was both presented and discussed in light of the research purposes. For example, the purpose of the research study in Example 17 was "to give a morphometric description of the interproximal bone between the anterior maxillary teeth of subjects with class III facial deformity, who were candidates for segmented Le Fort I osteotomy" (Brito et al. 2019). The Discussion move is, therefore, embedded in the Results move in experimental-based dentistry subdisciplines, as evidenced by the findings. This finding contrasts with Vathanalaoha and Tangkiengsirisin's (2018) study of the move structure in international experiment-based dental RA abstracts, which indicated that the Discussion move follows the Results move in most international dentistry journals (48\%).

\subsubsection{Move 5: Conclusion}

The Conclusion move is essential in all the eight dentistry subdisciplines since it occurred in 112 of 119 (94.11\%) RA abstracts (Table 3). When investigating the frequency of this move in each subdiscipline, however, intradisciplinary variations appeared in the Periodontics and Restorative Dentistry (76.47\%), Oral Sciences (88.23\%) and Oral and Maxillofacial Surgery (94.11\%) RA abstracts (Table 3). This move is considered 'conventional' in these subdisciplines since its occurrence in each subdiscipline was between $60 \%$ and $99.99 \%$. 
(18) We conclude that ALA administration alleviated the AP-induced heart injury and improved cardiac structure and function, and therefore this agent may be of potential therapeutic value in protecting cardiac tissue from systemic injury caused by AP. (Oral Sciences)

We conclude that our results are within the published ranges, and the variation in condylar uptake was less than 5\% in 37/44 patients, and in none was it $9 \%$ or more. (Oral \& Maxillofacial Surgery)

The opening sentence of this move represents a prototypical instance of the Conclusion move in most RA abstracts rather than a Discussion move, as found by Vathanalaoha and Tangkiengsirisin's (2018) study of dentistry RA abstracts, since the findings showed that the following expressions were frequently used: "to conclude", "it was concluded" and "in summary".

As stated earlier, the international journals Vathanalaoha and Tangkiengsirisin (2018) investigated were in the General Dentistry, Periodontics and Endodontics sub-fields. The findings related to the latter two sub-fields in the present study indicated that the Conclusion move was employed by most RA abstracts rather than the Discussion move (Table 3).

(20) It can be concluded that porcine-derived membrane can be used for vertical soft tissue thickening with substantial gain in tissue height. (Periodontics \& Restorative Dentistry)

(21) Infiltration of long-acting betamethasone and dexamethasone resulted in decreased postoperative pain experience. Dexamethasone was more effective in alleviating pain within the first 24-hour period after treatment... The QOL in the 2 groups receiving corticosteroids was higher than that in the placebo group. (Endodontics)

Moreover, the RA abstracts in the Endodontics journal guidelines were structured with the Conclusion move being last and following the Results move: I-P-M-R-C (Table 2). This finding also contrasts with Suntara and Usaha's (2013) study, which indicated that this move was optional in linguistics but conventional in applied linguistics. It also contrasts with Hyland's (2000) finding that 60 per cent of physics and engineering RA texts employ the Purpose-Method-Result move sequence. Hyland (2000) argues that the Conclusion move is increasingly used in RA abstracts.

The two steps Implications/Suggestions for further research and Limitations are non-essential (optional) in all the eight dentistry subdisciplines since they occurred in less than 60 per cent of the 119 RA abstracts (17.65\% and 9.24\% 
respectively). Notably, however, none of the authors in the Operative Dentistry sub-field employed the Implications/Suggestions for further research step (Table 3). The disappearance of this step in the 17 Operative Dentistry RA abstracts is uncanny. The lack of this step could be ascribed to the fact that this step is not required in laboratory research studies. This step followed move 5 in the other seven sub-fields of dentistry RA abstracts, as shown below.

(22) In the present indication and methodologic setup, computer-assisted protocols did not show an advantage over conventional protocols in terms of time or financial savings [Conclusion]. The temporal and financial expenses should be put into perspective to potential benefits [Suggestions]. (Periodontics \& Restorative Dentistry)

(23) No patients had a recurrence of ankylosis during follow up [Conclusion]. Our results suggest that simultaneous arthroplasty and distraction osteogenesis is feasible in this group [Implications]. (Oral \& Maxillofacial Surgery)

The authors here emphasize new contributions and/or important aspects of their study or observation(s). Thus, the Implications/Suggestions step is non-essential in seven of the eight dentistry subdisciplines. Conversely, the Limitations step appeared only in the Orthodontics RA abstracts, with a frequency of 64.7 per cent (11 of 17 Orthodontics RA abstracts); thus, it is treated as a conventional step in this subdiscipline since its occurrence exceeded 60 per cent (Table 3). Although the acknowledgement of limitations in a scientific study is an important step in the RA abstract, it was not required in the other seven subdisciplines. Notably, the authors of the Orthodontics subdiscipline employed this move because it was required in the journal guidelines (Table 2). As the Orthodontics journal guidelines state, "subtitles for the Abstract include Background/Objectives, Materials/Methods, Results, Limitations, Conclusions/Implications". Thus, authors of Orthodontics are required to present the Limitations step after the Results move (move 4) and before the Conclusion move (move 5).

(24) [Limitations] Although sample size (15 patients, 30 teeth) was adequate according to the initial power calculation, borderline significances may indicate lack of power or large variability among the samples. (Orthodontics)

[Limitations] The participation rate of only 62 percent, the disparate availability of records $(T 0, T 1)$, the fact that the patients were not treated at exactly the same time period and that no untreated control group is available. (Orthodontics) 
This finding contrasts with Karapetjana and Rozina's (2016) study of the move structure in a General Dentistry journal, which revealed that this step is merged with the Conclusion move. As the abstract was structured following journal guidelines, authors are required to note "the limitations implicit in the study" (ibid.: 12) when writing the Conclusion move.

Based on the move-analysis findings of previous studies of dentistry RA abstracts and my analyses of RA abstracts in the eight dentistry subdisciplines, a proposed move structure model (Table 3 ) for the textual organization of the abstract in these subdisciplines is suggested. The proposed model for dentistry RA abstracts consists of four obligatory moves, P-M-R-C, except for the last move, Conclusion, which is conventional in Oral Sciences, Oral and Maxillofacial Surgery, Periodontics, and Restorative Dentistry RA abstracts. These four conventional moves were the most preferred in Suntara and Usaha's (2013) study of the different moves in 200 RA abstracts of linguistics and applied linguistics, although there were variations in the Conclusion move, which was conventional in applied linguistics but optional in linguistics. This finding contrasts with Shamsabadi et al.'s (2014) study of Esthetic and Restorative Dentistry RA abstracts written by native speakers, which indicated that abstracts must include the three conventional moves Method-Result-Conclusion. Although the Introduction/Background move is essential in some dentistry subdisciplines, it is optional in others. Thus, although the combinations of moves/steps vary across the eight dentistry subdisciplines, four moves occurred frequently. This result contrasts with Vathanalaoha and Tangkiengsirisin's (2018) study, which revealed a five-move structure (B-P-M-R-D) in dentistry RA abstracts. The Limitations step precedes the Conclusion move and is treated as an essential step in RA abstracts of the Orthodontics subdiscipline, but it is not a required step in the other six subdisciplines. Finally, the Implications/Suggestions step follows the Conclusion move and is not a required step in the Operative Dentistry RA abstracts, although it is non-essential (optional) in the other seven dentistry subdisciplines.

Intradisciplinary variations/similarities for move length in each RA abstract in the eight dentistry subdisciplines are presented and discussed next to provide a detailed picture of key moves in each subdiscipline.

\subsection{Intradisciplinary variations/similarities in move length}

The analysis of the length of each move aimed to investigate the move(s) occupying the most text space. I embedded the three 'Steps' (Table 4) under their relevant moves to avoid confounding the study results since annotating these separately is more useful when dealing with full-length RAs. 
The findings revealed that the Methods and Results (moves 3-4) moves comprised 67.22 per cent of the text space (Table 4). The highest word counts for the Methods and Results moves occurred in the Prosthodontics and Operative Dentistry RA abstracts respectively. Thus, most of the information in the dentistry RA abstracts was provided in these two moves since each comprised more than 25 per cent of the text space.

\begin{tabular}{|l|l|r|r|r|r|r|r|}
\hline & Move & Move 1 & Move 2 & Move 3 & Move 4 & Move 5 & \\
\hline No. & Subdiscipline(s) & $\begin{array}{l}\text { Introduction/ } \\
\text { Background } \\
\text { (Optional) }\end{array}$ & Purpose & Method & Results & Conclusion & $\begin{array}{l}\text { Word } \\
\text { count }\end{array}$ \\
\hline 1 & Oral Sciences & 460 & 398 & $\mathbf{1 , 4 3 3}$ & 945 & 432 & 3,668 \\
\hline $2-3$ & $\begin{array}{l}\text { Periodontics } \\
\text { and Restorative } \\
\text { Dentistry }\end{array}$ & 149 & 454 & $\mathbf{8 3 4}$ & $\mathbf{8 5 7}$ & 394 & 2,688 \\
\hline 4 & Endodontics & 546 & 484 & $\mathbf{1 , 4 6 1}$ & $\mathbf{1 , 3 7 8}$ & 655 & 4,524 \\
\hline 5 & $\begin{array}{l}\text { Operative } \\
\text { Dentistry }\end{array}$ & 16 & 501 & $\mathbf{2 , 2 8 7}$ & 1,250 & 662 & 4,716 \\
\hline 6 & Prosthodontics & 136 & 505 & $\mathbf{1 , 8 3 8}$ & $\mathbf{1 , 7 6 3}$ & 670 & 4,912 \\
\hline 7 & $\begin{array}{l}\text { Oral/ } \\
\text { Maxillofacial }\end{array}$ & 462 & 463 & $\mathbf{1 , 2 3 3}$ & 725 & 565 & 3,448 \\
\hline 8 & Surgery & & & & & & \\
\hline & Wrthodontics & 173 & 471 & $\mathbf{1 , 7 9 7}$ & $\mathbf{1 , 5 9 2}$ & 858 & 4,891 \\
\hline & Pords & 1,942 & 3,276 & $\mathbf{1 0 , 8 8 3}$ & $\mathbf{8 , 5 1 0}$ & $\mathbf{4 , 2 3 6}$ & 28,847 \\
\hline
\end{tabular}

Table 4: Move length in the eight dentistry subdisciplines

According to the number of words within a move-tag, the Methods and Results moves occupied the most text space in the eight dentistry subdisciplines compared to the other moves. This is not surprising because most dentistry RAs are experimental in nature. Experimental dentistry studies require a large amount of text for the Methods and Results moves because the authors describe several aspects in the Methods section and their corresponding findings in the Results section, including participants, tools, techniques, software, and statistical procedures. Moreover, as stated earlier, the authors of experimental-based studies are required to present the findings of their analyses along with an interpretation and discussion of the findings in light of the research purposes. The discussion of Methods and Results in a scientific RA abstract is crucial. This finding supports Rashidi and Meihami's (2018) study of the rhetorical moves in RA abstracts of the Scientometrics Journal publications during four decades, 1978 to 2017, which 
was framed by Hyland's (2000) five-move model. The researchers found that the Method and Results sections contained most of the information in RA abstracts. Conversely, the move that provided the least information (i.e. used the least text space) in the present study was the Introduction, while it was the Conclusion in Rashidi and Meihami's (2018) study of RA abstracts in the Scientometrics Journal. This reflects disciplinary-specific variations in move length.

\section{Conclusion and implications}

The findings showed that $112(94.12 \%)$ of 119 dentistry RA abstracts employed the four-move conventional structure P-M-R-C, with the Introduction/ Background move being essential in three subdisciplines (Oral Sciences, Endodontics, and Oral and Maxillofacial Surgery) and optional in the other five subdisciplines. This indicates that a well-structured dentistry RA abstract must include all four structural units. The proposed move structure model (Table 3) for the eight dentistry subdisciplines revealed that there are no major intradisciplinary variations in the rhetorical four-move structure across all the eight dentistry subdisciplines. This finding contrasts with previous studies of dentistry RA abstracts (Shamsabadi et al. 2014, Vathanalaoha \& Tangkiengsirisin 2018). Shamsabadi et al.'s (2014) study of the move structure in the Esthetic and Restorative Dentistry journal revealed that a dentistry RA abstract should possess the three conventional moves Method-Result-Conclusion, but they did not indicate whether the Purpose was essential. By contrast, Vathanalaoha and Tangkiengsirisin's (2018) study of General Dentistry, Periodontics and Endodontics subdisciplines included the Purpose move but replaced the Conclusion move with the Discussion: P-M-R-D. The contribution of the present study, therefore, is the modification of existing move structure models and its application to intradisciplinary genre and a specific component of the article, the abstract.

However, there were intradisciplinary variations in the other moves/steps. First, the Introduction/Background move is considered conventional in three dentistry subdisciplines (Oral Sciences, Endodontics, and Oral/ Maxillofacial Surgery) and non-obligatory (or optional) in five subdisciplines (Operative Dentistry, Prosthodontics, Orthodontics, Periodontics, and Restorative Dentistry). Second, the Research Gap step is not required in the Operative Dentistry and Orthodontics subdisciplines but is non-essential (optional) in the Oral Sciences, Periodontics, Restorative Dentistry, Endodontics, Prosthodontics, and Oral and Maxillofacial Surgery subdisciplines. Third, subdisciplinary differences were found in the use of embedded Method-Result moves in one dentistry subdiscipline, Oral and Maxillofacial Surgery. Fourth, the Conclusion move is 
conventional in Oral Sciences, Oral and Maxillofacial Surgery, Periodontics, and Restorative Dentistry RA abstracts but obligatory in the other four dentistry subdisciplines. Fifth, the Limitations step precedes the Conclusion move and is an essential step in the Orthodontics subdiscipline but not required in the other seven subdisciplines. Finally, the Implications/ Suggestions step is not required in the Operative Dentistry RA abstracts, but it is non-essential (optional) in the other seven dentistry subdisciplines.

The results also showed that the Methods and Results moves used the most text space $(67.22 \%)$ in the eight dentistry subdisciplines, surpassing the other moves in terms of length. This indicates the crucial role of these two moves.

These findings are limited to the eight dentistry subdisciplines examined in the present study. The claim, therefore, whether the moves/steps are essential, conventional, or optional applies to the present study sample. In other words, the findings are contingent on the size and representativeness of the sample and on the period when the RAs were published, i.e. 2018-2019. The findings may, however, provide invaluable insights for novice dentistry scholars attempting to publish their research work in high-ranking journals. They may also contribute to the fields of discourse and genre studies and English for Specific or Academic Purposes (ESP/EAP) courses. Dentistry ESP/EAP students must be aware of the conventions set by their discourse community by being encouraged to discuss the generic structure variations in RA abstracts of dentistry subdisciplines. ESP/ EAP courses must focus on the common generic features of abstracts in dentistry subdisciplines, such as the four-move conventional structure and the optional Introduction/Background move. Because the introduction move rarely occurred in five of the eight dentistry subdisciplines, EAP tutors must draw learners' attention to the communicative functions of this move in an abstract, particularly pointing out the communicative function of the research gap. The proposed move structure model P-M-R-C for the RA abstracts in the field of dentistry can act as a guide for novice dentistry authors. Future studies can investigate variations in the move structure of different RA sections across several dentistry subdisciplines. The proposed move-analysis model for dentistry RA abstracts can be employed in similar investigations of other academic disciplines.

\section{Acknowledgments}

The author is indebted to the two anonymous reviewers for their insightful and helpful comments. The author also wishes to express his gratitude to both the Deanship of Scientific Research at King Saud University and the Research Centre at the Faculty of Arts for funding the present study. He also thanks RSSU at King Saud University for their technical support. 


\section{References}

Amnuai, W. (2019) 'Analyses of rhetorical moves and linguistic realizations in accounting research article abstracts published in international and Thai-based journals.' $S A G E$ Open, 1-9. DOI: 10.1177/2158244018822384.

Bhatia, V. (1993) Analyzing Genre: Language Use in Professional Settings. London: Longman.

Biber, D., Connor, U. and Upton, T. (2007) Discourse on the Move: Using Corpus Analysis to Describe Discourse Structure. Amsterdam and Philadelphia: John Benjamins.

Brito, L., Olate, S., Villa, J., Navarro, P., Haidar, Z. and de Moraes, M. (2019) 'Interproximal bone in maxillary anterior teeth in subjects with Class III facial deformity: Are there options for segmental maxillary osteotomy in "surgery first"?' British Journal of Oral and Maxillofacial Surgery 57(2), 140-144. DOI: 10.1016/j.bjoms.2018.10.287.

Can, S., Karabacak, E. and Qin, J. (2016) 'Structure of moves in research article abstracts in applied linguistics.' Publications 4(3), 1-16. DOI: 10.3390/publications4030023.

Cross, C. and Oppenheim, C. (2006) 'A genre analysis of scientific abstracts.' Journal of Documentation 62(4), 428-446. DOI: 10.1108/00220410610700953.

Dos Santos, M. B. (1996) 'The textual organization of research paper abstracts in applied linguistics.' Text-Interdisciplinary Journal for the Study of Discourse 16(4), 481-500. DOI: 10.1515/text.1.1996.16.4.481.

Ferguson, G. (2013) 'English for medical purposes.' In: Paltridge, B. and Starfield, S. (eds) The Handbook of English for Specific Purposes. West Sussex, UK: WileyBlackwell. 243-261.

Guide for Authors (2021) British Journal of Oral and Maxillofacial Surgery. Online document. Retrieved on 12 March $2021<$ https:/www.elsevier.com/journals/britishjournal-of-oral-and-maxillofacial-surgery/0266-4356/guide-for-authors>.

Huang, J. C. (2018) 'Marine engineering and sub-disciplinary variations: A rhetorical analysis of research article abstracts.' Text \& Talk 38(3), 341-363. DOI:10.1515/text2018-0002.

Hyland, K. (2000) Disciplinary Discourses: Social Interactions in Academic Writing. London: Longman.

Hyland, K. (2006) English for Academic Purposes: An Advanced Resource Book. London and New York: Routledge.

Instructions to authors (2021) European Journal of Orthodontics. Online document. Retrieved on 12 March 2021 <https://academic.oup.com/ejo/pages/General_ Instructions>.

Kanoksilapatham, B. (2005) 'Rhetorical structure of biochemistry research articles.' English for Specific Purposes 24(3), 269-292. DOI:10.1016/j.esp.2004.08.003.

Kanoksilapatham, B. (2013) 'Generic characterization of civil engineering research article abstracts.' 3L: Southeast Asian Journal of English Language Studies 19(3), 1-10.

Karapetjana, I. and Rozina, G. (2016) 'Rhetorical structure of the research article in dentistry.' Russian Linguistic Bulletin 3(7), 10-14. DOI:10.18454/RULB.7.40.

Khansari, D., Chan, S. H., Chan, M. Y. and Tan, H. (2016) 'Regularities and irregularities in rhetorical move structure of linguistics abstracts in research articles.' 3 L: Language, Linguistics, Literature 22(1), 39-54.

Lave, J. and Wenger, E. (1991) Situated Learning: Legitimate Peripheral Participation. New York: Cambridge University Press.

Li, Q. and Pramoolsook, I. (2015) 'Research article abstracts in two subdisciplines of Business: Move structure and hedging between Management and Marketing.' English Language Teaching 8(1), 52-62. DOI:10.5539/elt.v8n1p52. 
Martín, P. M. N. (2003) 'A genre analysis of English and Spanish research paper abstracts in experimental social sciences.' English for Specific Purposes 22(1), 25-43. DOI:10.1016/S0889-4906(01)00033-3.

Maswana, S., Kanamaru, T. and Tajino, A. (2015) 'Move analysis of research articles across five engineering fields: What they share and what they do not.' Ampersand 2, 1-11. DOI:10.1016/j.amper.2014.12.002.

Ngai, S. B. C., Singh, R. G. and Koon, A. C. (2018) 'A discourse analysis of the macrostructure, metadiscoursal and microdiscoursal features in the abstracts of research articles across multiple science disciplines.' PloS one 13(10), e0205417. DOI:10.1371/ journal.pone.0205417.

Pho, P. D. (2008) 'Research article abstracts in applied linguistics and educational technology: A study of linguistic realizations of rhetorical structure and authorial stance.' Discourse Studies 10(2), 231-250. DOI:10.1177/1461445607087010.

Rashidi, N. and Meihami, H. (2018) 'Informetrics of Scientometrics abstracts: A rhetorical move analysis of the research abstracts published in Scientometrics journal.' Scientometrics 116(3), 1975-1994. DOI:10.1007/s11192-018-2795-6.

Salager-Meyer, F. (1990) 'Discoursal flaws in medical English abstracts: A genre analysis per research-and text-type.' Text-Interdisciplinary Journal for the Study of Discourse 10(4), 365-384. DOI:10.1515/text.1.1990.10.4.365.

Samraj, B. (2005) 'An exploration of a genre set: Research article abstracts and introductions in two disciplines.' English for Specific Purposes 24(2), 141-156. DOI:10.1016/j.esp.2002.10.001.

Shamsabadi, R., Riahipour, P. and Rasekh, A. E. (2014) 'A genre analysis on the rhetorical moves in dentistry research abstracts.' The Iranian EFL Journal 10(3), 419-432.

Suntara, W. and Usaha, S. (2013) 'Research article abstracts in two related disciplines: Rhetorical variation between linguistics and applied linguistics.' English Language Teaching 6(2), 84-99. DOI: /10.5539/elt.v6n2p84.

Swales, J. (1990) Genre Analysis: English in Academic and Research Settings. Cambridge: Cambridge University Press.

Swales, J. (2004) Research genres: Explorations and Applications. Cambridge: Cambridge University Press.

Tankó, G. (2017) 'Literary research article abstracts: An analysis of rhetorical moves and their linguistic realizations.' Journal of English for Academic Purposes 27, 42-55. DOI:10.1016/j.jeap.2017.04.003.

Tseng, F. P. (2011) 'Analyses of move structure and verb tense of research article abstracts in applied linguistics journals.' International Journal of English Linguistics 1(2), 27-39. DOI:10.5539/ijel.v1n2p27.

Vathanalaoha, K. and Tangkiengsirisin, S. (2018) 'Genre analysis of experiment-based dental research article abstracts: Thai and international journals.' $3 L$ : Language, Linguistics, Literature 24(3), 1-14. DOI:10.17576/3L-2018-2403-01.

Von Fraunhofer, J. A. (2010) Research Writing in Dentistry. Oxford: Wiley \& Sons.

Zand-Moghadam, A. and Meihami, H. (2016) 'A rhetorical move analysis of TEFL thesis abstracts: The case of Allameh Tabataba'i University.' Issues in Language Teaching 5(1), 1-23.

Zand-Vakili, E. and Kashani, A. F. (2012) 'The contrastive move analysis: An investigation of Persian and English research articles' abstract and introduction parts.' Mediterranean Journal of Social Sciences 3(2), 129-137. DOI:10.5901/mjss.2012. v3n2.129. 


\section{Dentistry texts referred to:}

Achilleos, E., Rahiotis, C., Kavvadia, K. and Vougiouklakis, G. (2019) 'Clinical evaluation of two different prevention programs in adults depending on their caries risk profile: One-year results.' Operative Dentistry 44(2), 127-137. DOI:10.2341/17-164-C.

Afacan, B., Öztürk, V. Ô., Geçgelen Cesur, M., Köse, T. and Bostanci, N. (2019) 'Effect of orthodontic force magnitude on cytokine networks in gingival crevicular fluid: A longitudinal randomized split-mouth study.' European Journal of Orthodontics 41(2), 214-222. DOI:10.1093/ejo/cjy068.

Bock, N. C. (2019) 'Long-term ( $\geq 15$ years) effects of Class II treatment: A longitudinal and cross-sectional study on signs and symptoms of temporomandibular disorders.' European Journal of Orthodontics 41(2), 172-179. DOI:10.1093/ejo/cjy040.

Brennan, P., Mak, J., Massetti, K. and Parry, D. (2019) 'Communication between the transverse cervical nerve $(\mathrm{C} 2,3)$ and marginal mandibular branch of the facial nerve: a cadaveric and clinical study.' British Journal of Oral and Maxillofacial Surgery 57(3), 232-235. DOI:10.1016/j.bjoms.2018.10.289.

Brito, L., Olate, S., Villa, J., Navarro, P., Haidar, Z. and de Moraes, M. (2019) 'Interproximal bone in maxillary anterior teeth in subjects with Class III facial deformity: Are there options for segmental maxillary osteotomy in "surgery first"?' British Journal of Oral and Maxillofacial Surgery 57(2), 140-144. DOI:10.1016/j.bjoms.2018.10.287.

Fernandes, A., Faria, M., Oliveira, A., Coelho, P. B. and Pereira, J. (2019) 'Assessment of relative uptake by mandibular condyles in a "normal" population.' British Journal of Oral and Maxillofacial Surgery 57(3), 251-254. DOI:10.1016/j.bjoms.2018.12.016.

Geddes, A., Laverick, S., McBride, A. and McIntyre, G. (2019) 'Severity and outcome assessment score: A useful tool for auditing orthognathic surgery.' British Journal of Oral and Maxillofacial Surgery 57(3), 246-250. DOI:10.1016/j.bjoms.2018.10.291.

Goodfellow, M. and Burns, A. (2019) 'Relation between facial fractures and socioeconomic deprivation in the north east of England.' British Journal of Oral and Maxillofacial Surgery 57(3), 255-259. DOI:10.1016/j.bjoms.2018.11.021.

Guarnieri, R. (2019) 'Long-term (15 to 20 Years) outcomes of papillae preservation flap surgery in esthetic areas.' International Journal of Periodontics \& Restorative Dentistry 39(3), 349-359. DOI:10.11607/prd.4017.

Høyvik, A. C., Lie, B. and Willumsen, T. (2019) 'Dental anxiety in relation to torture experiences and symptoms of post-traumatic stress disorder.' European Journal of Oral Sciences 127(1), 65-71. DOI:10.1111/eos.12592.

Kunz, F., Schweitzer, T., Große, S., Waßmuth, N., Stellzig-Eisenhauer, A., Böhm, H., Meyer-Marcotty, P. and Linz, C. (2019) 'Head orthosis therapy in positional plagiocephaly: Longitudinal 3D-investigation of long-term outcomes, compared with untreated infants and with a control group.' European Journal of Orthodontics 41(1), 29-37. DOI:10.1093/ejo/cjy012.

Kvalheim, S. F., Xenaki, V., Kvalheim, A., Lie, S. A., Marthinussen, M. C., Strand, G. V. and Costea, D. E. (2019) 'Effect of glycerol on reconstructed human oral mucosa.' European Journal of Oral Sciences 127(1), 19-26. DOI:10.1111/eos.12590.

Liu, L., Leng, S., Yue, J., Lu, Q., Xu, W., Yi, X., Huang, D. and Zhang, L. (2019) 'EDTA Enhances stromal cell-derived factor $1 \alpha$-induced migration of dental pulp cells by upregulating chemokine receptor 4 Expression.' Journal of Endodontics 45(5), 599-605. e591. DOI:10.1016/j.joen.2019.01.006.

Ma, Y., Huang, Y., Zhu, S. and Li, Y. (2019) 'Simultaneous arthroplasty and distraction osteogenesis for the treatment of ankylosis of the temporomandibular joint and 
secondary mandibular deformities in children.' British Journal of Oral and Maxillofacial Surgery 57(2), 135-139. DOI:10.1016/j.bjoms.2018.11.016.

Paphangkorakit, J., Kanpittaya, K., Pawanja, N. and Pitiphat, W. (2019) 'Effect of chewing rate on meal intake.' European Journal of Oral Sciences, 127(1), 40-44. DOI:10.1111/ eos. 12583 .

Puisys, A., Zukauskas, S., Kubilius, R., Barbeck, M., Razukevičius, D., Linkevičiene, L. and Linkevičius, T. (2019) 'Clinical and histologic evaluations of porcine-derived collagen matrix membrane used for vertical soft tissue augmentation: A case series.' The International Journal of Periodontics \& Restorative Dentistry 39(3), 341-347. DOI:10.11607/prd.4097.

Raghavan, S., Philip, K., Batra, P. and Marcusson, A. (2019) 'Aesthetic perceptions and psychosocial impact of malocclusion: comparison between cleft and non-cleft patients and their parents.' European Journal of Orthodontics 41(1), 38-45. DOI:10.1093/ejo/ cjy022.

Ren, Z. H., Wu, K., Wang, Y., Tian, Z. W. and Hu, J. Z. (2019) 'Role of a two-step suture in the prevention of postoperative transoral salivary fistulas during reconstruction of the oral cavity.' British Journal of Oral and Maxillofacial Surgery 57(2), 164-168. DOI:10.1016/j.bjoms.2019.01.005.

Ross, B. and Ross, S. B. (2019) 'Cryopreserved umbilical cord allograft for root coverage of gingival recession defects: A case series.' International Journal of Periodontics \& Restorative Dentistry 39(3), 391-397. DOI:10.11607/prd.3876.

Ruf, S. and Schneider, D. (2019) 'A randomized controlled clinical trial comparing conventional and computer-assisted implant planning and placement in partially edentulous patients. Part 3: Time and cost analyses.' International Journal of Periodontics \& Restorative Dentistry 39(3), e71-e82. DOI:10.11607/prd.4146.

Sehirli, A. Ö., Aksoy, U., Kermeoglu, F., Kalender, A., Savtekin, G., Ozkayalar, H. and Sayiner, S. (2019) 'Protective effect of alpha-lipoic acid against apical periodontitisinduced cardiac injury in rats.' European Journal of Oral Sciences 127(4), 333-339. DOI:10.1111/eos.12618.

Skjold, A., Schriwer, C. and Øilo, M. (2019) 'Effect of margin design on fracture load of zirconia crowns.' European Journal of Oral Sciences 127(1), 89-96. DOI:10.1111/ eos.12593.

Yang, Z., Gao, X., Zhou, M., Kuang, Y., Xiang, M., Li, J. and Song, J. (2019) 'Effect of metformin on human periodontal ligament stem cells cultured with polydopaminetemplated hydroxyapatite.' European Journal of Oral Sciences 127(3), 210-221. DOI:10.1111/eos.12616.

Yavari, H. R., Jafari, F., Jamloo, H., Hallaj-Nezhadi, S. and Jafari, S. (2019) 'The effect of submucosal injection of corticosteroids on pain perception and quality of life after root canal treatment of teeth with irreversible pulpitis: A randomized clinical trial.' Journal of Endodontics 45(5), 477-482. DOI:10.1016/j.joen.2019.01.005.

Zheng, Y., Yin, N., Zhao, Z., Wang, Y., Wu, D., Li, H., Jiang, C., Tong, H. and Song, T. (2019) 'Two-stage maxillary distraction osteogenesis using a modified external device: clinical outcome and complications.' British Journal of Oral and Maxillofacial Surgery 57(3), 236-241. DOI:10.1016/j.bjoms.2018.11.020. 
Hesham Suleiman Alyousef is Associate Professor in the Department of English and Literature at King Saud University in Riyadh, Saudi Arabia. He has over 30 years of experience teaching ESL/EFL. Currently, he teaches and supervises several postgraduate students and works as an editor and a reviewer in refereed journals. Hesham Alyousef has published three book chapters and papers in refereed journals. His research interests include academic literacies, systemic functional linguistics, multimodal discourse analysis, metadiscourse, assessment and evaluation tools for ESL/EFL students, and the use of Web 2.0 technology in higher education.

Address: Hesham Suleiman Alyousef, 3752 Ghazwat thi AlAshirah, AlMughrizat, Riyadh 12482-6683, Saudi Arabia. [e-mail: hesham@ksu.edu.sa] 